\title{
Linguistic and spatial processings in solving three-term series problem
}

\author{
HIROSHI YAMA ${ }^{1}$
}

Department of Educational Psychology, Faculty of Education, Kyoto University, Sakyo-ku, Kyoto 606

\begin{abstract}
The purpose of this study is to identify linguistic and spatial processings in solving threeterm series problem by testing relations between this task and two verification tasks, one comparing sentences against pictures, and the other comparing sentences against kana letters (Japanese syllabary). First, two premises of three-term series problem were presented successively and 35 college students were asked to indicate whether three terms were ordered linearly or not. Next, they participated in the two verification tasks. Twenty-six subjects whose RT data were individually fit to one of component models for the main task were classified into linguistic or spatial group by the value of two parameters. These parameters represented very stable strategies. There was a significant association between the linguistic-spatial grouping and the RT difference between the verification tasks. Moreover, subjects with large value of parameter for spatial models took longer time to solve the sentence-kana verification task than to solve the sentence-picture verification task. It was concluded that subjects who adopted spatial strategy were good at spatial processing and that, the poorer they were at linguistic processing, the larger were their spatial parameters.
\end{abstract}

Key words: three-term series problem, linguistic processing, spatial processing, strategies, component models.

" $\mathrm{A}$ is larger than $\mathrm{B}$, and $\mathrm{B}$ is larger than $\mathrm{G}$, what is the largest?" This task is called three-term series problem. There was a controversy on the form of the representation: "linguistic (Clark, 1969)" versus "spatial (Huttenlocher, 1968)".

According to the former, a problem will be solved more rapidly if its pivot term (B) is presented as subject in the second premise. This effect is easily conceivable because the pivot search is necessary to solving. But according to the latter, it will be solved more rapidly if its third term is presented as subject in the second premise. This effect is called "endanchor", and is opposite to the pivot search principle. Huttenlocher, Eisenberg, and Strauss (1968) claimed that

1 I wish to express my gratitude to Dr. Takao Umemoto, Professor of Konan Women's College for his helpful comments and guidance throughout this research. I also wish to express my gratitude to Dr. Noboru Sakano, Professor of Kyoto University, and Dr. Hisao Fujita, Professor of Osaka University, for their valuable suggestions. the effect occurs because the third term must be brought from the statement to the extralinguistic situation, that is to say, spatial representation.

This controversy was settled by componential approach (Sternberg, 1980; Yama, 1986). Yama's task was to indicate whether three terms of two premises presented successively were ordered linearly or not. Reaction times (RT) were measured as dependent variables. Linguistic models which had "pivot search in the second premise (PS2)" parameter, or spatial models which had "endanchor (EA)" parameter were supposed. The value of the parameters and the problem types are shown in Table 1. As a result, about two-thirds of subjects' data were consistent with the linguistic models, while other subjects' with spatial models.

In the present research, to test the validity and the generality of the parameters, relations between RTs of this task and those of other tasks would be 
Table 1

Problem types, value of parametcrs, and mean reaction times for correct responses

\begin{tabular}{|c|c|c|c|c|c|c|}
\hline \multirow{2}{*}{ Premises } & \multicolumn{5}{|c|}{ Parameters } & \multirow{2}{*}{ Mean RTs } \\
\hline & PS2 & EA & PSGR & PSPR & PSDI & \\
\hline $\mathrm{A}>\mathrm{B}, \mathrm{B}>\mathrm{C}$ & 0 & 1 & 1 & 1 & 1 & 2710 \\
\hline $\mathrm{A}>\mathrm{B}, \mathrm{C}<\mathrm{B}$ & 1 & 0 & 0 & 1 & 1 & 2592 \\
\hline $\mathrm{B}>\mathrm{A}, \mathrm{B}>\mathrm{C}$ & 0 & 1 & 0 & 0 & 1 & 2541 \\
\hline $\mathrm{B}>\mathrm{A}, \mathrm{C}<\mathrm{B}$ & 1 & 0 & 1 & 0 & 1 & 2538 \\
\hline $\mathrm{B}>\mathrm{C}, \mathrm{A}>\mathrm{B}$ & 1 & 0 & 1 & 0 & 0 & 2482 \\
\hline $\mathrm{B}>\mathrm{C}, \mathrm{B}<\mathrm{A}$ & 0 & 1 & 0 & 0 & 0 & 2330 \\
\hline $\mathrm{C}<\mathrm{B}, \mathrm{A}>\mathrm{B}$ & 1 & 0 & 0 & 1 & 0 & 2404 \\
\hline $\mathrm{C}<\mathrm{B}, \mathrm{B}<\mathrm{C}$ & 0 & 1 & 1 & 1 & 0 & 2504 \\
\hline
\end{tabular}

Note. PS2 = pivot search in the second premise; EA=end-anchor; PSGR=grammatical pivot search; PSPR = propositional pivot search ; PSDI=directional pivot search.

All reaction times are expressed in milliseconds.

specified. The main task was the same as that of Yama (1986). The letters of F, N, and $S$ were adopted as terms and "largersmaller" as comparatives. For rclations, the sentence-picture verification task (SPV; Clark \& Chase, 1972) would be adopted. The basic paradigm of this task is that a subject observes a sentence, such as "Plus is above star", and then a picture, either ${ }_{+}^{*}$ or ${ }_{*}^{+}$, and indicates whether the sentence is true or not.

This task is advantageous for two reasons. One is that it seems to require constructing the similar representation of the sentence to that of three-term series problem (cf. MacLeod, Hunt, \& Mathews, 1978). The other is that a modification of the task can be used for testing the relations between the parameters and the linguistic-spatial processings. In this new task, instead of a picture, a phonetic sign, kana, that is the Japanese syllabary, which would represent the pronunciation of the alphabet letters would be presented (SKV).

Following predictions can be made about the RT data: (a) RT data which are fit to spatial models will be correlated with those of SPV, while those which are fit to linguistic models will be correlated with those of SKV. (b) Subjects whose data are fit to spatial models will take longer time to solve SKV than SPV, while those whose data are fit to linguistic model will take longer time to solve SPV. (c) $\mathrm{E} \Lambda$ parameter cstimate corresponding to the duration of bringing the third term will be correlated with RT of SPV, while PS2 parameter estimate corresponding to the duration of the pivot search, with that of SKV.

\section{Method}

Subjects. Thirty-five students of Kyoto University, of which 15 were females, participated in all the tasks.

Stimuli. The stimuli of three-term series problem were following. The letters of " $F$ ", " $N$ ", and " $S$ " were used as three terms and "larger-smaller" as comparatives. Premises, such as " $\mathrm{F}$ is larger than $\mathrm{N}$ " were presented on the screen of $10 \mathrm{~cm} \times 14 \mathrm{~cm}$. The eight problem types, shown in Table 1, were constructed by varying whether (1) the comparative in the first premise was "larger" or "smaller", (2) the comparative in the second premise was "larger" or " smaller", (3) the order of two premises was "A-B, B-C", or " $\mathrm{B}-\mathrm{C}$, $A-B$ ". And eight partial order problem types were constructed by exchanging the adjectives of second premises of the linear 
order problems. Moreover, six kinds of problems were made by changing threc letters' order for each type. Therefore, the number of the problems was 96 .

In SPV, instead of each second premise of the main task, a pictures consist of two letters that were same as of the first premise such as, F

$$
\mathrm{N}
$$

was presented. 2 The stimuli were of four pairs which were formed by varying whether (1) the comparative in the premise was "larger" or "smaller", (2) the term which was made as "larger one "by the premise was above or below. From the combinations of three letters, six kinds of problems were made for each type. So, the number of this task was 24. In SKV, instead of each picture, two terms were described in kana.

Procedure. The subjects were tested individually. First, each subject participated in three-term series problem. Each trial started one second after he or she was ready. First of all, the first premise was presented for 2.5 seconds. Three seconds after the first premise was got turned off, the second premise was presented. From that time, he or she was asked to indicate whether three terms were ordered linearly or not, and to push one of the two buttons. RTs were measured in millisecond. If he or she couldn't respond within six seconds, the second premise was turned off, and the response was regarded as error even if it was correct. After the main task, he or she took part in SPV. In this task, instead each second premise of the main task, a picture was presented for each trial. He or she was asked to indicate if

2 This is not the genuine sentence picture verification task, because the picture does not represent the largeness of the terms. However, as Handel, De Soto, and London (1968) pointed out, a larger term is thought to be put on the top of a axis in one's representation. Therefore, the picture in this study must be analogous to a representation constructed by subjects. the letter, which was termed larger one, was above the smaller one or not by pushing one of the two buttons. The number of trials was 24. At last, SKV was executed. In this task, instead of a picture, kanas describing two letters were presented. The number of trials was 24 , too.

\section{Results and Discussion}

The range of error rate of the main task was from $1.8 \%$ to $14.5 \%$ for each subject. Mean RT of it for each problem are shown in Table 1. That of SPV was $601 \mathrm{~ms}$ and that of SKV was $702 \mathrm{~ms}$.

\section{Testing of Models}

To cach of the basic two parameters, one of the thrce parameters, which are of "pivot search in the first premise" component, are added. If the first premise is retained word for word, the search will be easier when the pivot is grammatically the same as in the second premise. The value of "grammatical pivot search (PSGR)" parameter reflects this difficulty. If the first premise is encoded into a propositional form, the search will be easier when the pivot is the subject. The value of "propositional pivot search (PSPR) " reflects this difficulty. If the terms of the first premise are seriated from the "larger" to the "smaller" in retaining, the search will be easier when the pivot is supposed to be the "larger" one in the first premise. The value of "directional pivot search (PSDI)" reflects this difficulty. So, six alternative component models are supposed. The value of these parameters were shown in Table 1.

As dependent variable of each subject, median of correct RTs for each problem type was used. The proportion of variance in each subject's data accounted for by each model $\left(R^{2}\right)$ was calculated by stepwise multiple regression. For each subject, a model of which parameter estimates were all positive, and whose 
Table 2

Number of subjects of each group and $k$ of optimal model for cach group's mean RTs

\begin{tabular}{ccc} 
Groups & $\begin{array}{c}\text { Number of } \\
\text { subjects }\end{array}$ & $\begin{array}{c}R^{2} \text { of } \\
\text { optimal model }\end{array}$ \\
\hline PS2-PSGR & 5 & $.768^{*}$ \\
PS2-PSPR & 3 & $.854^{*}$ \\
PS2-PSDI & 9 & $.881^{*}$ \\
EA-PSGR & 3 & .694 \\
EA-PSPR & 1 & $.805^{*}$ \\
EA-PSDI & 5 & $.918^{*}$
\end{tabular}

Table 3

Inner correlations of each parameter for individual subjects by odd-even technique

\begin{tabular}{cl}
\hline Parameters & $r$ \\
PS2-EA & $.746^{* *}$ \\
PSGR & $.392^{*}$ \\
PSPR & .198 \\
PSDI & .353
\end{tabular}

Note. Correlations of PS2 and EA were calculated together, because they were interdependent.

$R^{2}$ was the most was regarded as his or her optimal model, only that the $R^{2}$ of that was less than .3. Nine subjects had no optimal model, because the $R^{2}$ of any model was less than the criterion. Twenty-six subjects were divided into six groups for their optimal models. The number of subjects and $R^{2}$ of each optimal model for the mean RT data of each group are shown in Table 2. Individual differences in solving such a kind of task were clearly observed. These results were consistent with those of Yama (1986).

To testify the inner-subject strategic consistency, inner-correlation of each parameter estimate was calculated by odd-even technique. The results of 26 subjects were shown in Table 3 . The higher a correlation coefficient was, the more the strategy represented by the parameter was consistent in a subject. Because of perfect dependency, those of EA and PS2 parameters were calculated
Table 4

Correlations between reaction times of three-term series problem and those of SPV or of SKV

\begin{tabular}{cccc}
\hline & $\begin{array}{c}\text { Total } \\
(n=26)\end{array}$ & $\begin{array}{c}\text { Linguistic } \\
\text { models' } \\
\text { group } \\
(n=17)\end{array}$ & $\begin{array}{c}\text { Spatial } \\
\text { models' } \\
\text { group } \\
(n=9)\end{array}$ \\
\hline SPV & .384 & $.538^{*}$ & .053 \\
SKV & $.487 *$ & $.654^{* *}$ & .054
\end{tabular}

Note, SPV $=$ sentence-picture verification task; $\mathrm{SKV}=$ sentence-kana verification task.

Table 5

Number of subjects sorted by models of three-term series problem and by RT difference between SPV and SKV

\begin{tabular}{lcc}
$\begin{array}{c}\text { Three-term } \\
\text { series problem }\end{array}$ & $\begin{array}{c}\text { Shorter } \\
\text { RTs } \\
\text { in SPV }\end{array}$ & $\begin{array}{c}\text { Shorter } \\
\text { RTs } \\
\text { in SKV }\end{array}$ \\
\hline Linguistic models & 11 & 6 \\
Spatial models & 9 & 0
\end{tabular}

together, by regarding EA estimates as negative of PS2. The correlation of PS2EA parameters was the highest and significant. So, they were thought to represent comparatively lasting strategies of a subject. They must be based on one's intelligence. Other correlations were not so high, though that of PSGR parameter was significant. The strategies represented by these parameters were less stable.

\section{Correlations}

Because only EA and PS2 parameters represented stable processings, the correlations of main interest would be of the two parameters.

First, the correlations between the mean RT of the main task and those of SPV and SKV were calculated, and were shown in Table 4. Not consistent with the prediction (a), in spatial groups, the main task and the verifications were not significantly correlated. This suggested that subjects of spatial groups solved the 
verification tusks differently from the main task. Perhaps it was becalse, in the verification tasks, it was not necrssary for them to bring the third term into spatial representation.

Next, the validity was tested by correlations between the parameter estimates and RTs of the verification tasks. But no correlations were significant, not supporting the prediction (c).

Rather, the linguistic-spatial grouping reflected the RT difference between SPV and SKV, supporting the prediction (b). Table 5 shows the association betwcen the grouping of the main task and that br RT difference between SPV and SKV (in which was mean RT shorter). Though, because of relative ease in SPV, this association was not high, it was significant. Tschuprow's measure was $.40\left(\chi^{2}(26)=4.13, p<.05\right)$. This result suggested that E.1-PS2 parancters reflected a subject's relative skilluulness in the linguistic and spatial processing.

Moreover, though PS2 parameter estimate was not correlated with the RT difference, the correlation between EA parameter estimate and the RT difference (RT of SKV minus that of SPV) was significant, and the coefficient was $.74(d f=9, p<.05)$. This would be interpreted as follows: EA parameter estimate of a subject became longer, not because he or she was good at spatial processing, but because poor at linguistic processing. Perhaps such a subject took a spatial strategy for his or her relative roodness at spatial processing, but bocartse of the poorness at linguistic processing, he or she took longer time in bringing the third term into the spatial representation if it was presented as object in the second premise, for it took linguistic processing to make the premise available for the bringing.

\section{References}

Clark, H. H. 1969 Linguistic processes in deductive reasoning. Psychological Review, 76, 387-404.

Clark, H. H., \& Chase, G.W. 1972 On the process of comparing sentences against pictures. Cognitive Psychology, 3, 472-517.

Handel, S., De Soto, C. B., \& London, M. 1968 Reasoning and spatial representations. Journal of Verbal Learning and Vorbal Behavior, 7, 351-357.

Huttenlocher, J. 1968 Constructing spatial images: A stratcgy in reasoning. Psychological Revicu, 75, 550-560.

Huttenlocher, J., Eisenberg, K., \& Strauss, S. 1968 Comprehension: Relation between perceived actor and logical subject. Journal of Verbal Learning and Verbal Behavior, 7, 523-530.

MacLeod, C. M., Hunt, E. B., \& Mathews, N. N. 1978 Individual differences in the verification of sentence-picture relationships. Journal of Verbal Leaming and Verbal Behavior, 17, 493-507.

Sternberg, R.J. 1980 Representation and process in lincar syllogistic reasoning. Journal of Experimental Psychology: General, 109, 119-159.

Jama, H. 1986 Stratcgies used in three-term series problem. Japanese Journal of Psychology, 57, 156-162. (In Japanese with English abstract) (Received March 5, 1987; accepted July 11, 1987) 